\title{
El Kavalierstour de Juan V por Europa: génesis, precedentes y significado de un viaje frustrado
}

\author{
Pilar Diez del Corral Corredoira*
}

\author{
El «Kavalierstour» De Juan V por Europa: Génesis, PReCEDentes \\ Y SIGNIFICADO DE UN VIAJE FRUSTRADO
}

\section{Resumen}

En este artículo se estudia la génesis, desarrollo y fracaso del ambicioso proyecto de lo que se ha dado en llamar Grand Tour que ideó Juan V durante los primeros años de su reinado y que no solo se convirtió en un asunto que dividiría a su corte, sino que también afectó a la visión de su papel y el de Portugal en el tablero europeo. Se avanzará una nueva hipótesis sobre la naturaleza de dicho viaje y su imbricación en la tradición europea, que refuta parcialmente la visión historiográfica imperante. Se aportan, asimismo, nuevos documentos que arrojan luz sobre la percepción del viaje desde la perspectiva francesa y que revelan nuevos detalles sobre la logística de la estancia real en Roma.

\section{John V's European “Kavalierstour”: Genesis, Models and Meaning OF A FAILED JOURNEY}

\section{Abstract}

This article deals with the genesis, development and failure of the ambitious project, typically known as a Grand Tour, that John V planned in the earlier years of his reign. The journey caused strong divisions within his court and had an impact on the vision of his own role and Portugal's in the European arena. A new hypothesis is presented regarding the nature of that journey and its links with the European tradition that partially refutes the current historiographical approach to the topic. New documents are also presented that shed some light on the subject from the French point of view, and which also reveal new particulars about the royal stay in Rome.

Diez del Corral Corredoira, P., «El Kavalierstour de Juan V por Europa: génesis, precedentes y significado de un viaje frustrado», Acta/Artis. Estudis d'Art Modern, 6, 2018, págs. 97-111

Palabras Clave: Grand Tour, Kavalierstour, Juan V, Portugal, viaje

KeYworDs: Grand Tour, Kavalierstour, John V, journey

* Este trabajo se enmarca en el proyecto de investigación ACAF/ART IV

«Cartografías analíticas, críticas y selectivas del entorno artístico y monumental del área mediterránea en la edad moderna» (HAR201566579-P), financiado por el Ministerio de Economía y Competitividad. 
1. Jean Ranc

D. Juan $V$

de Portugal,

c. 1729, óleo

sobre lienzo,

$109 \times 91 \mathrm{~cm}$.

Museo Nacional

del Prado,

Madrid.

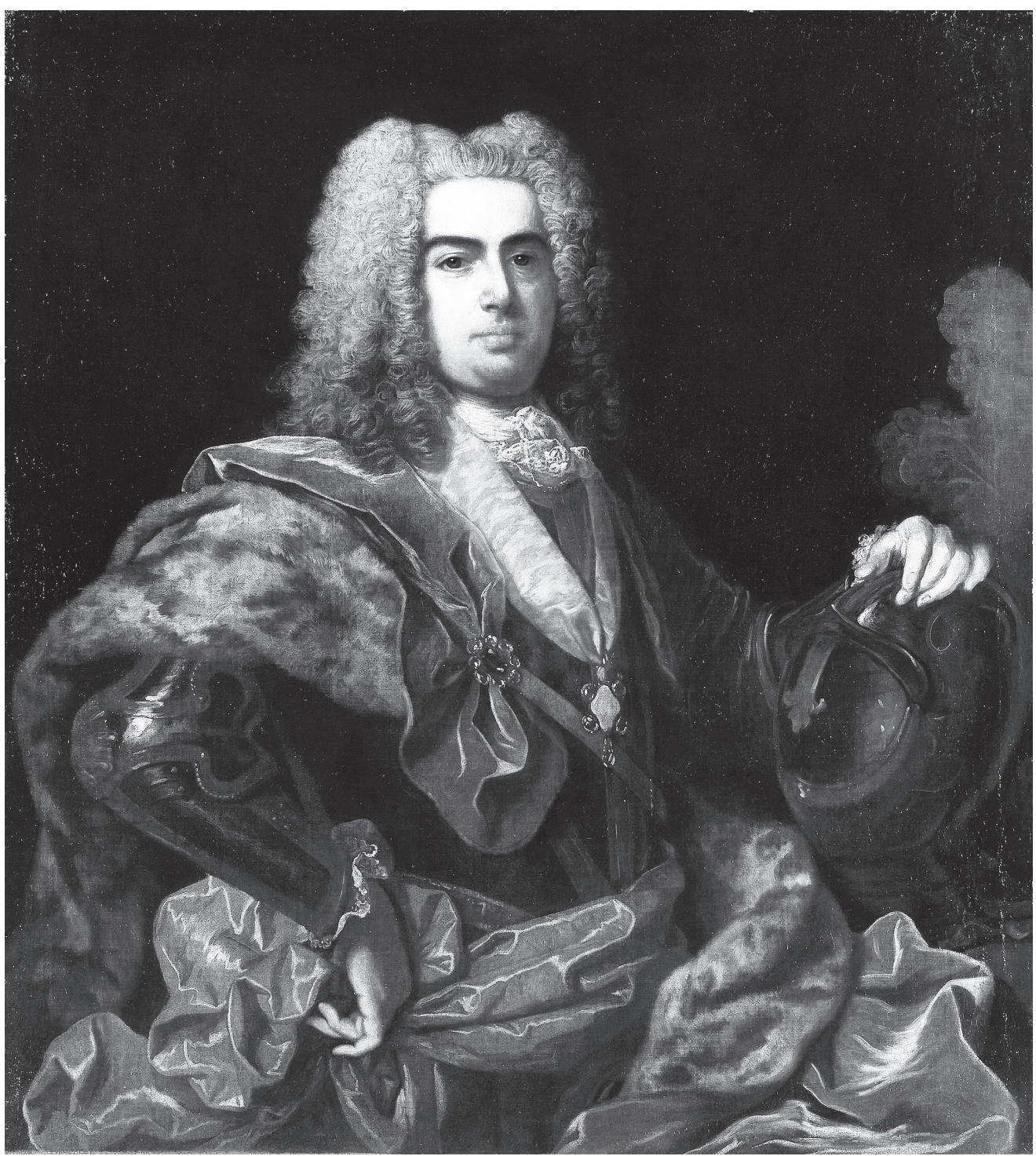

El 9 de diciembre de 1706 moría en Alcántara el rey Pedro II de Braganza (1683-1706), dejando su imperio al infante D. Juan (ilustración 1), príncipe de Brasil. La ceremonia que lo aclamaría era fruto de un cuidado plan iniciado en torno al 1705-1706 y orquestado por $\mathrm{D}$. Tomás de Almeida (Lisboa, 1670-1752), futuro patriarca de Lisboa y secretario de Estado desde 1704. ${ }^{1}$ El nuevo rey sería consagrado siguiendo la antigua tradición de la dinastía de Avís concedida por la bula de 1428 del papa Martín V y reafirmada por la bula Sedes Apostolica (1436) de Eugenio IV. Los reyes lusos podrían ser coronados siguiendo el ceremonial del Pontifical Romano siempre y cuando expresasen su obediencia al papa. También serían ungidos por el arzobispo de Braga en brazos y hombros, ceremonia que aludía a su carácter militar. ${ }^{2} \mathrm{D}$. Tomás de Almeida habría encargado la traducción de la bula de Eugenio IV, teniendo ya presente la cercana sucesión de

1. Da Costa De BARbosa, F.A., Elogio historico: vida e morte do eminentissimo e reverendissimo senhor cardeal D. Thomás de Almeida. Lisboa: Officina de Miguel Rodrigues, 1754.

2. Brásıo, A., «O problema da sagração dos monarcas portugueses», Anais da Academia Portuguesa de História, serie II, 12, 1962, págs. 39-40; y sobre el ceremonial: ARAúJo, A.C., «Ritualidade e poder na corte de D. João V: A génese simbólica do regalismo político», Revista de História das Ideias, 22, 2001, págs. 175-208, en particular págs.179-184. 
Pedro II, con el objetivo de vincular al nuevo rey a la idea de un origen divino y a la «missão providencial assinalada aos antepasados da casa real portugue$s a »$, y habría marcado así el inicio de un reinado excepcional para la casa de Braganza. ${ }^{3}$

Este particular ceremonial, que ponía el acento sobre la sacralización del poder real, señalaba el inicio del opulento período joanino, en el que el joven monarca absoluto gobernaría desde Lisboa con una renovada mirada sobre los asuntos europeos y, en concreto, sobre la Santa Sede. En Roma se conjuraban todos los deseos de equiparación de la Corona portuguesa con las grandes monarquías europeas, es decir, España, Francia y el Imperio, con las que Portugal quería presentarse en pie de igualdad a través de la concesión de una serie de privilegios que emanaban del papa.

A pesar de que la llegada al trono de Juan $\mathrm{V}$ (ilustración 2) se produjo en un momento de relativa calma, lo cierto es que las grandes potencias estaban inmersas en la Guerra de Sucesión española que había estallado en 1702. La guerra dividía Europa entre los aliados del archiduque Carlos, cuya coronación habría supuesto la continuidad de la rama habsbúrgica, y los de Felipe de Anjou, el cual gobernaba España, desde 1701, como Felipe V, y cuyo triunfo im-

plicaba el establecimiento de la dinastía borbónica en la Corona hispana, siguiendo los deseos expresados en el testamento del difunto Carlos II.

En una primera fase, Pedro II se había mantenido firme en su deseo de permanecer neutral en una guerra que sacudiría los cimientos del equilibrio de poderes en Europa; sin embargo, en 1703, tras firmar el Tratado de Lisboa, entra a formar parte de la Gran Alianza contra españoles y franceses al lado del Sacro Imperio, Inglaterra y las Provincias Unidas de Holanda. ${ }^{4}$ Posteriormente, con la firma del Tratado de Methuen, en el mismo año, une su destino al de Inglaterra por medio de una serie de acuerdos comerciales que serán muy criticados por algunos miembros de la nobleza, como D. Luís da Cunha (Lisboa, 1662 - París, 1749), uno de los diplomáticos más brillantes del XVIII portugués (ilustración 3), que veía en el acuerdo un acto de sumisión.

Este viraje convertía Portugal en la base de operaciones de la Gran Alianza, lo cual, además de responder a intereses estratégicos, se puede interpretar como un deseo patente del rey por entrar de lleno en la arena política europea al lado de importantes aliados. No obstante, las particulares condiciones de dicha alianza y lo súbito de la misma empujaron en cierto modo

3. Araújo, A.C., «Ritualidade e poder...», pág. 183; y véase también RibeIro, M. DE AzAmbujA, «Legitimar um rei com profecias: messianismo, milenarismo e profetismo no discurso político do Portugal moderno (séculos XVI-XVIII)", Magallánica, 2-3, 2015, págs. 74-95.

4. Sobre la Guerra de Sucesión y Portugal conviene mencionar los dos clásicos: Davis Francis, A., The first peninsular war, 1702-1713. Londres: E. Benn, 1975; y KAMEN, H., The War of Succession in Spain. Bloomington: Indiana University Press, 1969; y entre la abundante bibliografía más reciente: VV.AA., O Tratado de Methuen (1703): diplomacia, guerra, política e economia. Lisboa: Livros Horizonte, 2003; ClunY, I., D. Luís da Cunha e a ideia de diplomacia em Portugal. Lisboa: Livros Horizonte, 1999; idem, «A guerra de sucessão de Espanha e a diplomacia portuguesa», Penélope: Revista de Historia e Ciências Sociais, 26, 2002, págs. 63-92; RIBOT, L., «Portugal y la sucesión en España a finales del siglo XVII», en MARTíN MARCOS, D. (ed.), Monarquías encontradas. Estudios sobre Portugal y España en los siglos XVII y XVIII. Madrid: Sílex, 2013 , págs. 95-137.

2. Carlo Grandi (grabador) Regiae Celsitudine D. Emanuelis Joan $V$ Lusitaniae Regis fratis, 1729, grabado, $28,8 \times 19,8 \mathrm{~cm}$. Biblioteca Nacional de Portugal, Lisboa. 
3. Jan Baptist

Xavery

D. Luís da

Cunha, 1737,

mármol,

$80 \times 66 \times 31 \mathrm{~cm}$

Rijksmuseum,

Ámsterdam.

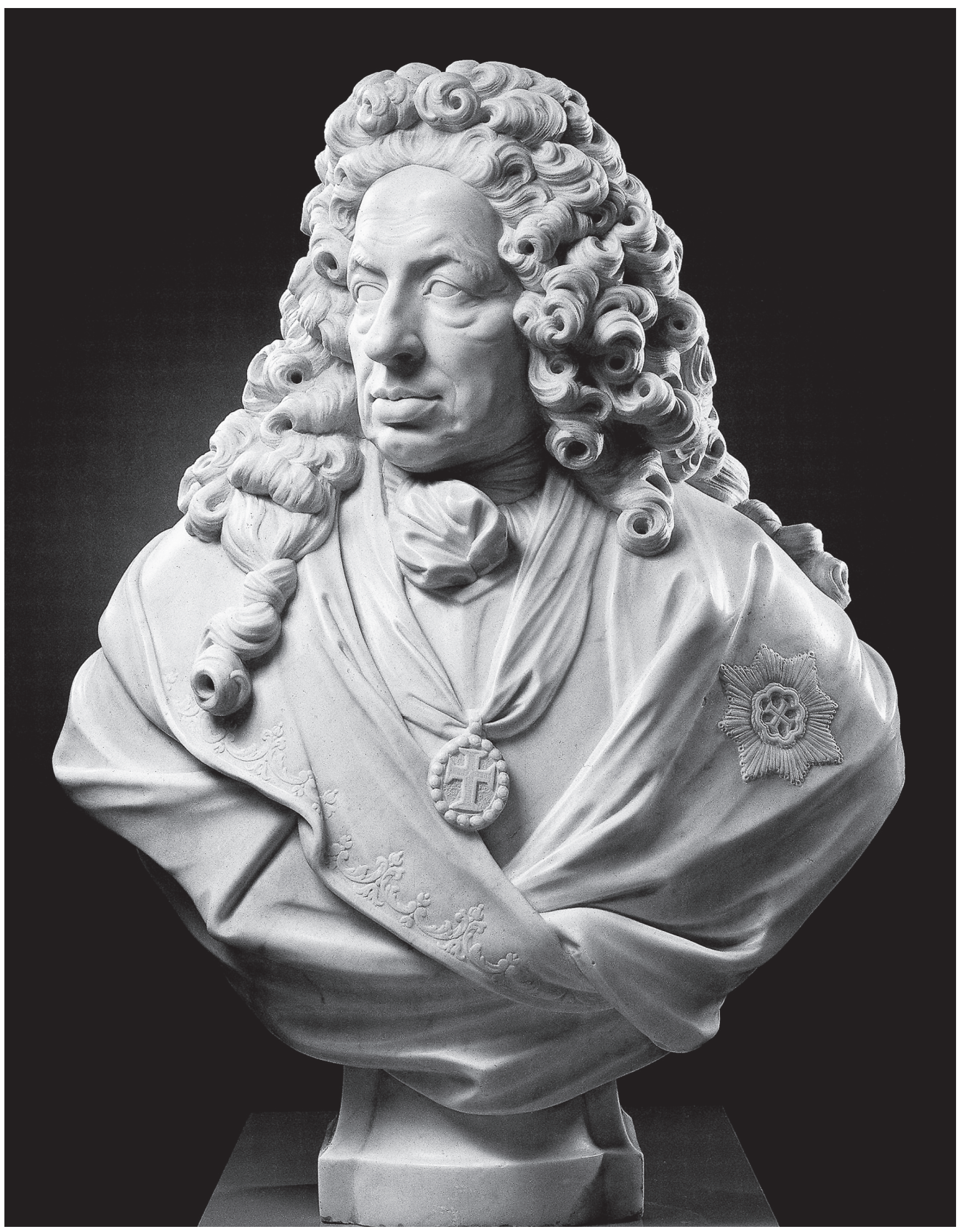

a Pedro II a publicar una suerte de explicación para sus súbditos, que aclaraba las razones que justificaban ese cambio. ${ }^{5}$ Juan $V$ heredó esta situación y su cuidadosa elección de embajadores y enviados para formar parte del Tratado de Utrecht demuestra su vivo interés en no ser un actor pasivo entre las grandes potencias y en mantener, por tanto, la voluntad de su padre en lo que a la guerra concernía. Con todo, y a la postre, los escasos réditos políticos y diplomáticos obtenidos de sus negociaciones favorecieron que el monarca luso se apartase y volviese a la clásica neutralidad anterior en los sucesivos conflictos de las décadas siguientes.

5. Justificación de Portugal en la resolución de ayudar a la ínclita nación española a sacudir el yugo francés y poner en el trono real de su Monarquía al Rey Católico Carlos III. Lisboa: [s.e.] 1704. 


\section{LA GÉNESIS DEL VIAJE DE JUAN V POR EUROPA}

En algún momento de los primeros años de reinado de Juan $V$ se diseñó un viaje por las cortes más importantes de Europa. El periplo se desarrollaría en dos años y tendría el objetivo de lograr que el monarca se informarse sobre los territorios, usos y costumbres de las diferentes ciudades europeas. Solo recientemente la historiografía ha comenzado a prestar atención a este viaje, que apenas aparecía mencionado y se consideraba una extravagancia o un peregrinaje a Roma ${ }^{6}$ La única cosa en la que había un cierto acuerdo era en el hecho de calificarlo como un Grand Tour, aunque el énfasis sobre la ciudad pontificia ha sido reevaluado hace poco. ${ }^{7}$ En este trabajo se defenderá que el viaje responde con mayor exactitud a una tradición europea bastante extendida en el área germánica conocida como el Kavalierstour, con su variante del Prinzenreise.

El concepto de Grand Tour está íntimamente ligado a la historiografía anglosajona y, aunque como término aparece también en otras lenguas, ${ }^{8}$ la definición canónica implica:

A Grand Tour is not a Grand Tour unless it includes the following; first a young British male patrician [...]; second, a tutor who accompanies his charge throughout the journey; third, a fixed itinerary that makes Rome its principal destination; fourth, a lengthy period of absence, averaging two or three years. ${ }^{9}$

A su lado el ámbito y los participantes del Kavalierstour son más flexibles, ya que este tenía objetivos diferentes en función del estatus y el rango del viajero, así como comprendía otros territorios, más allá de la península italiana. ${ }^{10}$ El Grand Tour sirve, además, a la rica aristocracia británica como medio de significarse social y patrióticamente: ninguna comunidad nacional de la época se valió del viaje de forma tal que este se convirtiese en un convencionalismo representativo propio, hasta el punto de que la misma terminología se asocia a una práctica considerada eminentemente británica. ${ }^{.1}$

La planificación del viaje de Juan V se mantuvo, con toda certeza, como un secreto reservado a su círculo más afín hasta muy cercana la fecha de partida, prevista para el 4 de octubre de 1715. El secretismo en torno al mismo se rompe entonces, cuando se empiezan a filtrar informaciones sobre la ruta y la duración, pero la génesis de este ambicioso tour europeo probablemente respondiese a un proyecto muy temprano que hasta la firma de la paz con España no pudo materializarse.

El viaje estaba pensado para una duración de dos años y la ruta estaba diseñada al detalle para hacer coincidir la llegada del rey con determinadas celebraciones del calendario festivo,

6. Raggi ha publicado extensamente sobre el reinado de Juan Vy ha llamado la atención en concreto sobre la necesidad de estudiar el impacto de ese viaje en el rey y en su política cultural. Véase con más referencias historiográficas RAGGI, G., «Italia e Portogallo: un incrocio di sguardi sull'arte della quadratura», en Alessandrini, N.; Russo, M.; SABATINI, G.; Viola A. (eds.), «Di buon affetto e comercio»: relaçãoes luso-italianas na Idade Moderna. Lisboa: CHAM, 2012, págs. 177-211, en particular, págs. 192-194; RAGGI, G., «Lasciare l'orma: os passos de Filippo Juvarra na cidade de Lisboa», en ALESSANDRINI, N.; Flor, P.; Russo, M; SABATINI, G. (eds.), «Le nuove sono tanto e tante buone, che dir non se pò». Lisboa dos italianos: história e arte (sécs. XIV-XVIII). Lisboa: CHAM, 2013, págs. 189-218.

7. Véase RAGGI, nota previa.

8. Groote Tour, Große Tour. LeIBetseder, M., Die Kavalierstour. Adlige Erziehungsreisen im 17. und 18. Jahrhundert. Colonia: Böhlau, 2004, págs. 18-23.

9. Redford, B., Venice and the Grand Tour. New Haven: Yale University Press, 1996, pág. 15.

10. Durante el absolutismo la figura del viajero se convirtió prácticamente en un actor más del juego diplomático, por ejemplo, en la corte francesa esos viajeros tenían un lugar preciso y adaptado dentro de la etiqueta de la corte, lo cual demuestra lo habitual de su presencia. LeIBETSEDER, M., Die Kavalierstour..., pág. 209.

11. LeIBETSEDER, M., «Educational Journey, Grand Tour», en European History Online (EGO), Leibniz Institute of European History (IEG), Mainz,11-11-2013. Disponible en http://www.ieg-ego.eu/leibetsederm-2013-en, URN: urn:nbn:de:01592013102901, pág. 4 con más referencias bibliográficas. 
como su visita a Venecia en pleno carnaval de 1717. El rey viajaría de incógnito bajo un nombre falso, el de «marqués de Meleses», ${ }^{12}$ aspecto que respondía a razones tanto de tipo práctico, ya que esta identidad le permitía llevar un séquito relativamente menor (entre 120 y 300 personas), como económico, ya que no al no ser el rey al que se acogía e invitaba, tanto este como las personas con las que se encontraba podían reducir, en parte, el gasto representativo, así como relajar el complejo protocolo de las precedencias. ${ }^{13}$

Formaban parte de su selecto grupo de viajeros los nobles más cercanos y afines: «oltre due camarieri che sono il Sr Marquese di Marialva e il Sr Conte di Unhão ancora il Sr Duca D. Jaime [de Cadaval] come suo cavallerizzo maggiore e il virtuoso et erudito Sr Conte di Ericeira». ${ }^{14}$ A este círculo más estrecho debió de pertenecer, en una primera fase de planificación, el infante D. Manuel, hermano menor de D. Juan, que formaría parte de la aventura. Dos Santos sostiene que el viaje se concibió como un proyecto diseñado en exclusiva para D. Manuel, ya que en realidad este pretendía alistarse en alguna guerra y hacer fortuna en Europa. ${ }^{15}$ Esta posibilidad no parece apoyarse en ninguna documentación conocida, y nada hace pensar que se tratase únicamente de una iniciativa realizada para el infante, sobre todo si se atiende a las fuentes que relatan el empeño de Juan V. Ello no excluye la perfecta adecuación del viaje a un periplo de claro componente educativo, que constituiría una excelente ocasión para la formación del infante al estilo de los Prinzenreisen. ${ }^{16}$

A pesar de que la duración del viaje, veinticuatro meses, permitía visitas dilatadas, es indudable que la ruta era muy ambiciosa. El rey dejaría Lisboa por tierra, atravesaría España y Francia, sin visitar ni Madrid ni París, para ir directamente a Flandes, de donde partiría hacia Inglaterra para conocer la corte inglesa. Regresaría al continente por Holanda y desde allí atravesaría Alemania y Austria y llegaría a Venecia en febrero de 1717. Pasaría la Cuaresma en Nápoles y la Semana Santa en Roma, donde se detendría hasta el Corpus Christi. Después, durante dos meses exploraría Florencia, antes de visitar Turín y otras ciudades italianas por el camino. En su viaje de regreso conocería las dos cortes borbonas, la parisina y la madrileña, sus antaño enemigos, para regresar a Lisboa a través de Andalucía. ${ }^{17}$

El viaje sufrió un primer retraso sobre la planificación original de octubre de 1715 y se pospuso hasta el 20 de febrero de 1716 - dato conocido por la correspondencia del nuncio Vincenzo Bicchi con la Santa Sede-, momento en el que ya estaban al corriente del mismo otras cortes europeas. ${ }^{18}$ A pesar de que la organización se hizo en secreto, o al menos es lo que se desprende de la correspondencia de Bichi, ello no impidió que pronto se levantasen voces contrarias a la "grande Idea», que venían tanto del propio Portugal como de otras cortes. ${ }^{19} \mathrm{El}$ bloque contrario al viaje estaba encabezado por el anciano y expertísimo duque de Cadaval, Nuno Álvares Pereira de Melo (Évora, 1638 - Lisboa, 1727), y por el secretario de Estado, Diogo Mendonça Corte-Real (Tavira, 1658 - Benfica, 1736), entre otros importantes nobles, mientras

12. Archivio Segreto del Vaticano (ASV), Segreteria di Stato, Portogallo, 72, fols. 363-364, carta de Bichi del 10 de diciembre de 1715. Citado por RAgGI, G., «Lasciare l'orma...», pág. 252.

13. Sobre el viaje de incógnito véase BENDER, E., Die Prinzenreise: Bildungsaufenthalt und Kavalierstour im höfischen Kontext gegen Ende des 17. Jahrhunderts. Berlín: Lukas, 2011, en particular, págs. 87-92.

14. ASV, Segreteria di Stato, Portogallo, 72, fols. 329-330, carta de Bichi del 27 de septiembre de 1715, citado por RAGGI, G., «Lasciare l'orma...», pág. 253.

15. Dos SAntos, J.E., «Valioso subsídio para a biografía do Infante D. Manuel, Irmão de João V», Olisipo, 115-116, 1966, págs. 5-14 (pág. 6).

16. Bender, E., Die Prinzenreise... El autor desarrolla pormenorizadamente los detalles logísticos de un viaje de esas características.

17. RAGGI, G., «Italia e Portogallo...», pág. 193, para ver la transcripción de la carta de Bichi con la referencia completa de la ruta.

18. ASV, Segreteria di Stato, Portogallo, 73, fols. 7-8, carta del 6 de enero de 1716. Citado por RAGGI, G., «Lasciare l'orma...», pág. 252.

19. ASV, Segreteria di Stato, Portogallo, fol. 39v, carta de 4 de febrero de 1716. Citado por RaGgI, G., «Italia e Portogallo...», pág. 194.

102 - Articles 
que el rey se apoyaba en algunos contemporáneos que compartían su interés y entusiasmo. ${ }^{20}$ El IV conde de Ericeira, Francisco Xavier de Meneses (Lisboa, 1673-1743), fue uno de sus apoyos más importantes en este proyecto. El conde había participado en la guerra al lado de Pedro II y había sido distinguido por su actuación en las batallas de 1708 y 1709. Además de sus éxitos militares, para entender su ascendencia sobre el rey es esencial señalar que el conde de Ericeira era muy respetado por su amplia cultura y su temprana pertenencia y activa presencia en la Academia dos Generosos, que sería el germen de la Academia Portuguesa de 1717. Sin duda, Juan $\mathrm{V}$ encontró en él un gran aliado y posiblemente fue la figura que inspiró al monarca tan particular decisión. ${ }^{21}$

La facción contraria al viaje llegó a conseguir el apoyo de la reina, María Ana de Austria (Linz, 1683 - Lisboa, 1754), que había sido designada por su esposo como regente mientras durase su periplo. A la reina la asistiría el cardenal Nuno da Cunha e Ataíde (Lisboa, 16641750), personaje de gran influencia en los primeros años del rey, así como el duque de Cadaval. Incluso, después del primer aplazamiento, se quedaría como apoyo de la reina el secretario de Estado, Corte-Real, que inicialmente estaba previsto que participase en el viaje por deseo del rey. ${ }^{22}$

Las razones que se esgrimían para evitar que el viaje se realizase se basaban en cuestiones de seguridad, tanto personal como nacional - puesto que el país podría encontrarse en una situación complicada a causa de la larga ausencia de su rey-. El duque de Cadaval llegó a escribir un informe en el que se detallaban aspectos económicos, debido al enorme desembolso que implicaba, y estratégicos, como una posible anexión española aprovechando la debilidad del país sin rey. ${ }^{23}$ Con probabilidad las primeras presiones surtieron efecto, por lo que se retrasó la salida desde octubre de 1715 hasta febrero de 1716, lo cual, presuntamente, sería lo que impulsó al infante D. Juan a abandonar Lisboa en secreto en noviembre de 1715, un mes después de la fecha inicial de partida. Este episodio desencadenó un largo período de enemistad entre los hermanos.

D. Manuel, no se sabe si de forma impulsiva o movido por la convicción de que el viaje no se realizaría nunca, decidió escapar de Lisboa en un barco inglés con rumbo a Ámsterdam. El joven pretendía alistarse para luchar contra los turcos y viajó con tres sirvientes y acompañado de su amigo íntimo Manuel Teles da Silva, hijo de João Gomes da Silva, el IV conde de Tarouca (Lisboa, 1671 - Viena, 1738). ${ }^{24}$ El conde sería la figura que los acogería en su primer destino, La Haya, donde era embajador. Allí entraron en contacto con D. Luís da Cunha, enviado especial para la firma del Tratado de Utrecht, que ejercería en adelante como protector del infante e intercedería para conseguir la paz entre los hermanos.

Las noticias del viaje del rey ya recorrían Europa y se comentaban en diferentes círculos; por ejemplo, en noviembre de 1715 Charles François Poerson (París, 1653 - Roma, 1725), director de la Academia de Francia en Roma, recoge en su habitual correspondencia con el duque d'Antin (París, 1665-1736), sobreintendente de los Edificios Públicos, nuevas informaciones sobre el viaje que han llegado gracias al nuncio:

20. RAgGi, G., «La circolazione delle opere della stamperia De Rossi in Portogallo», en AntinORI, A. (ed.), Studio d'architettura civile. Gli atlanti di architettura moderna e la diffusione dei modelli romani nell'Europa del Settecento». Roma: Quasar, 2013, págs. 143-163 (pág. 144).

21. El conde poseía un gabinete de física y participaba muy activamente en la organización de la biblioteca regia, ocupándose de asuntos relacionados con las matemáticas y las artes. FerReIRA FurTado, J., «D. João V e a década de 1720: novas perspectivas na ordenação do espaço mundial e novas práticas letradas», en Fragoso, J.; GouvEA, M. DE F., O Brasil Colonial, c. 1720 - c. 1821. Río de Janeiro: Civilização Brasileira, 2014, págs. 61-110 (pág. 93).

22. Agradezco a Giuseppina Raggi el acceso a esta información que forma parte de un trabajo inédito sobre la corte joanina, así como su disponibilidad para discutir diferentes aspectos de la controvertida figura del rey.

23. Para un mayor desarrollo del memorial véase Veríssimo Serrão, J., História de Portugal. Lisboa: Verbo, 1982, vol. v, pág. 247.

24. Su hermano era Fernando Teles da Silva, II marqués de Alegrete (Lisboa, 1662-1734). 
Le nonce du Pape, qui est en Portugal, a écrit au St. Père que le Roy avoit pris, malgré le Prince son frère et tous les conseils de ses Ministres, la ferme résolution de venir à Rome au printemps prochain; que, pour cet effet, ce rince a desjà fait remettre 500 milles de libres Romaines à Gesnes, ce que fait plus de deux millions de libres. L'on adjoute qu'il passera par la France, voulant faire le voyage par terre. Sa Sainteté le logera, à ce qu l'on croit, au Vatican. ${ }^{25}$

Apenas tres semanas después del oprobioso episodio del infante, las noticias ya habían llegado a la corte romana y desde allí a oídos del duque d'Antin en París. Resulta interesante ver cómo Poerson sabe que el rey se mantiene firme ante sus críticos, aunque no tiene planes concretos sobre la ruta, ya que en primavera el monarca estaría en Bélgica y preparado para cruzar el canal hasta la corte Estuardo, y no en Roma, como menciona en la carta. Asimismo habían llegado noticias de la provisión de fondos que estaba preparándose para costear el viaje.

El oro de Río de Janeiro y de Bahía se destinaría a cubrir el extraordinario gasto que se esperaba que se produjese. ${ }^{26}$ Brasil sufragaría lo que la historiografía posterior creería una extravagancia, aspecto que aprovecha el duque de Cadaval para avisar de los peligros de producirse la salida del Reino, ya que también se temía una insurrección americana por los altos impuestos que gravaban a sus súbditos brasileños. ${ }^{27}$

\section{LA VICTORIA DEL NO Y SUS CIRCUNSTANCIAS}

A pesar de la firmeza del rey, así como de la cuidada planificación, una serie de eventos, no se sabe si fortuitos, aprovechados por los contrarios al viaje o incluso favorecidos por ellos, fueron empujando la fecha de partida hasta su definitiva cancelación. Todavía la correspondencia del nuncio de finales de $1715 \mathrm{y}$ principios del 1716 parece confirmar la voluntad del rey. ${ }^{28}$ Por ejemplo, en diciembre de 1715 Poerson vuelve a escribir al duque d'Antin diciéndole:

Le Pape continue toujours à garder la chambre à cause du rhume qu'il prit lors qu'il fut à SaintPierre, où il visita les appartemens du Vatican pour y loger, à ce que l'on croit, le Roy de Portugal, en cas que ce Prince exécute le dessein qu'il a formé de venir à Rome. ${ }^{29}$

Donde se reitera la información que Poerson le había confiado en la otra misiva, en la que se mencionaba que el rey luso pasaría su estancia romana alojado en los palacios vaticanos. Se trata de un detalle de gran interés y que vendría a confirmar lo que se conoce por otras fuentes respecto al estado de los palacios ocupados por los legados portugueses en Roma, es decir, que no eran apropiados para al rey. ${ }^{30}$

25. Montaiglon A.; Guiffrey, J., Correspondance des directeurs de l'Académie de France à Rome avec les surintendants des Bâtiments. vol. Iv. París: Charavay Frères, 1893, carta 1933 de Poerson a Pardaillan, duque d'Antin, del 26 de noviembre de 1715 .

26. Buescu, A.I., «"O peregrino instruído”. Em torno de um projecto de viagem setecentista», Revista da Faculdade de Ciências Sociais e Humanas, 2, 1988, págs. 27-58 (pág. 32).

27. Verissimo Serrão, J., História de Portugal..., pág. 247.

28. RAGGI, G., «La circolazione...», pág. 143.

29. Montaiglon, A.; Guiffrey, J., Correspondance des directeurs..., carta 1935 de Poerson a Pardaillan, duque d'Antin, 3 de diciembre de 1715 .

30. En 1716 se encontraban en Roma el enviado especial, André de Melo e Castro (1668-1753), conde das Galveias, y el embajador extraordinario, D. Rodrigo de Sá e Meneses (1676 - Abrantes, 1733), marqués de Fontes. El primero residía en el palacio Cesarini, en Torre Argentina, que había sido habilitado ex profeso para Melo y que tan solo tres años después sería abandonado por un palacio de mayor envergadura y más acorde con la imagen de la Corona portuguesa en Roma, el 
La resistencia a la salida del monarca de su reino contaba en teoría con el apoyo de otras cortes, como el embajador francés Mornay y el duque de Orleans, regente de Francia, y esa facción acabó quebrando la voluntad de Juan V, que ya en la primavera de 1716 había renunciado a su «fississima regia volontà». ${ }^{31}$ Varios fueron los hechos que coadyuvaron, quizá de forma azarosa, a la cancelación definitiva del viaje y que están intrínsecamente ligados a Roma. En concreto, fueron la renovada amenaza turca en las costas de Morea y Corfú y la llamada de ayuda a las cortes cristianas realizada por Clemente XI lo que constituyó el diversivo principal.

La relación del pontífice con Portugal fue muy estrecha desde los últimos años de la contienda sucesoria española, en la que vio fracasar su proyecto de mediación y su plan de mantener la neutralidad. ${ }^{32}$ Portugal, de alguna manera, fue capaz de obtener una serie de privilegios importantes a pesar de haberse significado como aliada del bando imperial. En efecto, en febrero de 1716, casi providencialmente, el papa pide ayuda naval al rey por la acuciante amenaza otomana y este responde con enorme rapidez enviando una serie de naves. ${ }^{33}$ Estas no llegarán a tiempo para los primeros enfrentamientos, pero serán esenciales en la batalla de Matapán de 1717. Así las cosas, a lo largo de la primavera de 1716, momento en el cual el viaje debería de haberse materializado, el rey se ve inmerso en los preparativos del apoyo militar marítimo, de forma que la partida se va posponiendo. El 8 de julio, apenas unos días después de que las naos abandonaran Lisboa, con motivo del día de Santa Isabel de Portugal, el marqués de Fontes acudió a su triunfal audiencia papal con sus magníficas carrozas alegóricas, atravesando Roma. El mensaje era claro y potente, Portugal acudía al rescate como potencia marina y reino con una obvia misión espiritual: defender la cristiandad. Además del espinoso asunto del $p a-$ droado real, el marqués llevaba como embajada conseguir la división de Lisboa en dos diócesis y la elevación de la Capilla Real a Basílica Metropolitana y Patriarcal, y Clemente XI le concedió ambas, hecho que quedaría ratificado por la bula áurea, In Supremo Apostolatus Solio, del 7 de noviembre de 1716. Para entonces el viaje del rey yacía sepultado ante los éxitos diplomáticos de sus representantes.

\section{EL SIGNIFICADO DEL VIAJE Y SUS PRECEDENTES}

Aventurar qué habría sucedido si Juan V hubiese llegado a realizar su ansiado viaje por Europa resulta un ejercicio casi distópico, pero entender qué es lo que motivó ese viaje y su sentido en su reinado constituye una tarea que puede arrojar luz en especial en cuanto a política cultural se refiere.

El viaje de reyes no era una práctica muy habitual y cuando sucedía se debía sobre todo a cuestiones políticas o religiosas. Había, por ejemplo, viajes de Estado (sálvese el anacronismo),

palacio Sforza-Cesarini, en la actual vía Vittorio Emanuele. El marqués de Fontes se encontraba en un palacio, todavía hoy sin identificar, en la plaza Colonna, en el que se hallaba instalado desde 1712 con su pequeña corte de artistas.

31. ASV, Segreteria di Stato, Portogallo, 72, fol. 330. Citado por RAGGI, G., «Lasciare l'orma...», pág. 192. BUESCU, A.I., "“O peregrino instruído"...", pág. 32.

32. MARtín Marcos, D., «El proyecto de mediación de la Santa Sede como alternativa a la guerra de sucesión española», Revista de Historia Moderna. Anales de la Universidad de Alicante, 25, 2007, págs. 129-147.

33. ASV, Portogallo, Signatura 73, fol. 64, 27 de febrero de 1716; fols. 95r, 10or, 19 de marzo de 1716; fol. 183r, 13 de junio de 1716: «Lista da Esquadra que S. Mag. He servido mandar de socorro a santidade do Papa Clemente a favor das armas da Igreja», citado por Delaforce, A., «Giovanni V di Bragança e le relazioni artistiche e politiche del Portogallo con Roma», en Borghini, G.; VAsco Rocca, S., Giovanni V di Portogallo (1707-175o) e la cultura romana del suo tempo. Roma: Àrgos, 1995, págs. 21-39 (pág. 37, n. 39 y n. 40). Véase también Gazeta de Lisboa, 28, 11 de julio de 1716. 


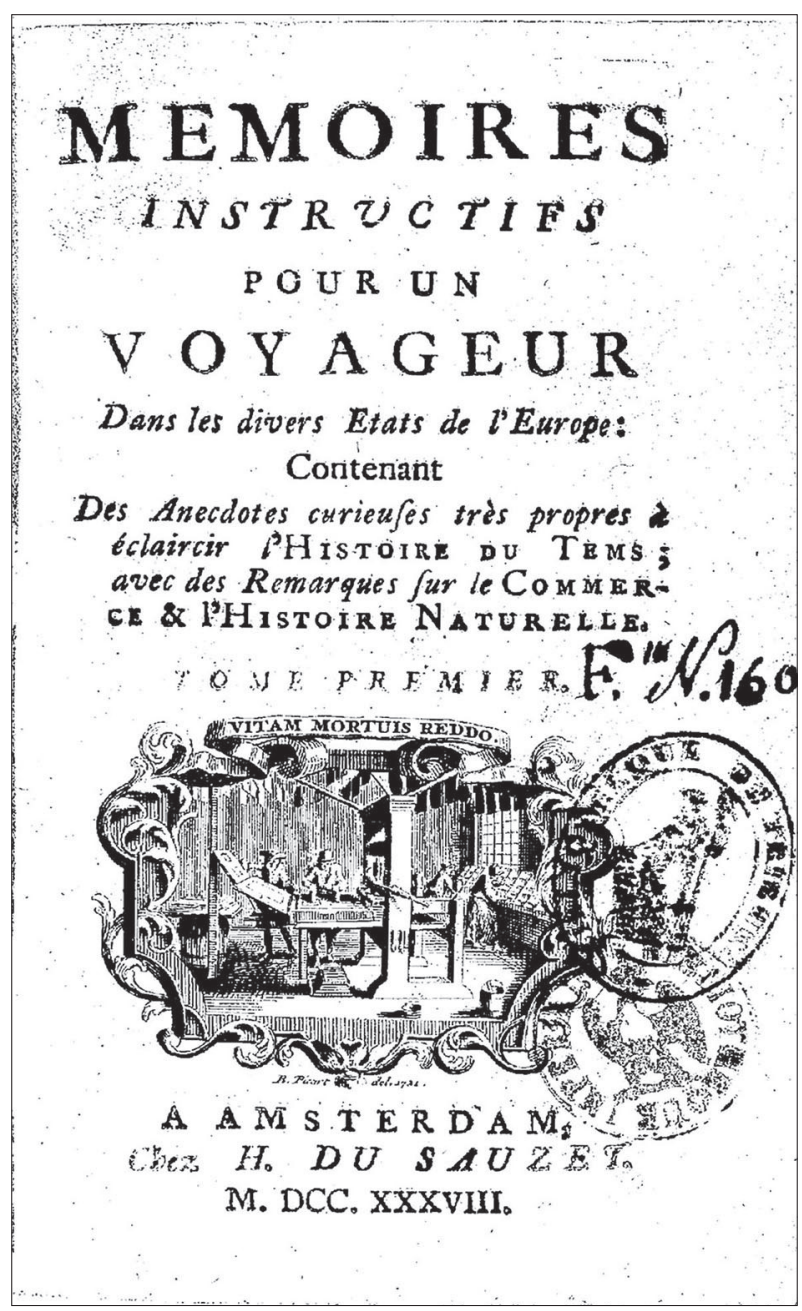

viajes pontificales o viajes de peregrinación, ${ }^{34}$ pero un viaje de esta amplitud y duración solía destinarse a los jóvenes príncipes y herederos con una función indudablemente formativa, y no conllevaba desatender las obligaciones para con sus súbditos. A pesar de la rareza, no fue Juan $\mathrm{V}$ el primero en planificar un viaje de esa envergadura; de hecho, sus predecesores lo hicieron con mayor éxito.

Se han señalado como posibles precedentes el viaje de Cosimo III de' Medici a España y Portugal entre 1668 y 1669 -que no estaba tan alejado en el tiempo como para ser considerado un modelo remoto- $y$, sobre todo, la Gran Embajada del zar Pedro el Grande, centrada en los países del norte -Alemania, Holanda e Inglaterra-, entre 1697 y $1698 .{ }^{35} \mathrm{El}$ caso ruso aparece señalado como ejemplo en las Mémoires instructifs (ilustración 4) del naturalista francés Charles Frédéric Merveilleux, que visitó Lisboa, y es indudable que el viaje del zar tiene concomitancias claras con el periplo luso. En primer lugar, porque se trataba de un dirigente en activo, no de un príncipe; y en segundo lugar, porque ambos comparten el mismo afán de conocimiento. ${ }^{36}$

En 1696, en la primera fase de la modernización de Rusia, que Pedro el Grande estaba tratando de implementar, se decidió enviar a cincuenta jóvenes de la nobleza a las cortes de Occidente para que fuesen educados, y no se les permitía volver sin un certificado firmado por un maestro extranjero que asegurase sus conocimientos. ${ }^{37}$ Sin embargo, cuan-
4. Charles Frédéric Merveilleux Mémoires instructifs. Ámsterdam: Sauzet, 1738 , portada. do el zar vio que eso no era suficiente optó por acudir en persona: su objetivo era visitar los grandes centros del saber para regresar a Rusia con los nuevos avances y estimular una renovación en todos los ámbitos. Es en este punto donde se ven claras las diferencias con el caso portugués: la Rusia de ese momento era todavía un país que arrastraba estructuras medievales, mientras que Portugal era un país moderno y rico que había conseguido la estabilidad tras la Restauração (1640).

Otro precedente, más directo y obvio y que hasta la fecha no ha sido explorado, es el de los príncipes electores de Sajonia, que tuvieron siempre presente la necesidad del viaje educativo. Ya Christian I (1586-1591), que fue educado por un maestro de corte en italiano, ${ }^{38}$ mandaría

34. La historiografía más tradicional convirtió el viaje de Juan V en una devota peregrinación a Roma, interpretación que ya fue refutada por Raggi y que a todas luces es insostenible: RAGGI, G., «Lasciare l'orma...», pág. 192.

35. RAgGI, G., «La circolazione...», pág. 159, n. 12; BuESCU, A.I., «“O peregrino instruído”...», pág. 33.

36. Véase GALE, G., «Leibniz, Peter the Great, and the modernization of Russia, or Adventures of a Philosopher-King in the East», Divinatio, 22, 2005, págs. 7-36 (pág. 13).

37. Massie, R.K., Peter the Great: His life and world. Nueva York: Knopf, 1980, págs. 149-150.

38. MARX, B., «Italianità und frühneuzeitliche Hofkultur: Dresden im Kontext», en MARX, B. (ed.), Elbflorenz: italienische Präsenz in Dresden 16.-19. Jahrhundert. Dresde: Kunst, 200o, págs. 7-36 (pág. 24). Sigismundo Kolreuter, médico de cabecera de Christian I, escribió una gramática a petición suya -Regolette e precetto dell grammatica volgare (1579) - para ayudarle en el estudio del italiano, que en aquella época empezaba a sustituir al latín entre los príncipes de habla alemana. Véase también LIEBER, M., «Die italienische Präsenz am Hofe Augustus des Starken und seiner Söhne. Erste Überlegungen», en MarX, B. (ed.), Elbflorenz..., pág. 143. 
a su hijo Johann Georg I (1585-1656) a Italia dentro de la tradición del Kavalierstour. ${ }^{39}$ La misma práctica se repetiría con su bisnieto Johann Georg IV de Sajonia entre 1685 y 1686 y, de nuevo, en 1690, pero con una mirada más amplia sobre el tablero europeo, ya que también visitaría París, Bruselas, Londres y varias ciudades alemanas, además de la ruta italiana. ${ }^{40}$

Sin embargo, el viaje que probablemente tuvo un impacto más directo en la corte de Lisboa fue el protagonizado por Federico Augusto I el Fuerte - elector de Sajonia (1694-1733) y rey de Polonia (1697-1706 y 1709-1733)—, hermano menor de Johann Georg IV. Partió el 19 de mayo de 1687, cuando todavía era príncipe, y no regresó a la que sería su opulenta capital, Dresde, hasta abril de 1689. Su Kavalierstour no solo abarcó Francia, España e Italia, sino que también le llevó a Portugal — quizá el viaje más completo y ambicioso, solo comparable con el proyecto posterior de Juan $\mathrm{V}-{ }^{41}$ Este es sin duda el modelo más cercano, ya que visitó Lisboa el año anterior al nacimiento del Braganza. En sus notas de viaje deja sus impresiones sobre la corte lisboeta, en la que confirió en numerosas ocasiones con el señor Lange, el cónsul danés, diversos representantes holandeses y el señor Simons, cónsul sueco. También tuvo audiencia con Pedro II y la reina, María Sofía de Palatinado-Neoburgo, con la que compartía lazos de sangre lejanos. ${ }^{42}$

La génesis del viaje de Juan $V$ es todavía hoy un misterio. No se conocen documentos que desvelen si la idea fue acuñada por el propio rey o por alguno de sus consejeros y se poseen pocos datos sobre su formación como príncipe, que parece que estuvo muy vinculada a los jesuitas. ${ }^{43}$ Lo que es indudable es que la mayoría de los personajes que apoyaron el proyecto, como el conde de Ericeira o el marqués de Fontes, eran bastante jóvenes cuando el elector de Sajonia visitó tierras portuguesas, con la excepción de algunos personajes de su círculo, como los diplomáticos D. Luís da Cunha o D. André de Melo e Castro. Este viaje se gestó en un entorno altamente intelectualizado y no tan político, a la vista de la resistencia que encontró en los miembros más concentrados en la dirección del Reino, como el duque de Cadaval o el secretario de Estado Corte-Real. Tradicionalmente se ha atribuido al conde de Ericeira la influencia mayor en cuanto a este viaje se refiere, pero no hay que olvidar que el mismo D. Luís da Cunha, destinado en La Haya, protegió al infante en su particular tour europeo y era la cabeza visible del círculo erudito al que pertenecía el conde y toda una red de diplomáticos que se enmarcaban en la República de las Letras. ${ }^{44}$

También se ha señalado la influencia del marqués de Fontes, aunque su ascendencia indudablemente creció al regreso, en 1718, de su exitosa embajada en Roma, es decir, ya cancelado el viaje. ${ }^{45}$ Es tentador aventurar que la partida del marqués en 1712, tras ser nombrado embajador extraordinario por Juan V en 1709, era una forma de enviar una primera avanzadilla a la corte pontificia e ir tanteando el terreno de su ansiado plan. Entre el séquito del marqués iban artistas, arquitectos y hasta un poeta, y una de las misiones era documentar visualmente y por escrito todos los eventos, celebraciones, palacios, iglesias, etcétera, que visitasen: ya en-

39. Lieber, M., «Die italienische Präsenz...», pág. 143, y Leibetseder, M., Die Kavalierstour..

40. Para un transcripción del diario de viaje del príncipe véase KELLER, K., «Mein Herr befindet sich gottlob gesund und wohl». Sächsische Prinzen auf Reisen. Leipzig: Leipziger Universitätsverlag, 1994, págs. 20-180.

41. El diario del príncipe de Sajonia está transcrito en Keller, K., «Mein Herr befindet...», págs. 181-39o. En principio iba a visitar también Inglaterra, Holanda, Dinamarca y Suecia.

42. Keller, K., «Mein Herr befindet...», págs. 272, 273, 441 y 442.

43. Nizza Da Silva, M.B., «D. João V», serie Reis de Portugal. Rio de Mouro: Círculo de Leitores, 2009, págs. 19-20; señala, además, que D. Luís da Cunha se lamentaba de la enorme influencia que tuvo en sus primeros años el futuro inquisidor general D. Nuno da Cunha de Ataíde.

44. Ferreira Furtado, J., «D. João V e a década...», págs. 83-84.

45. Así lo señalan Bottineau, Y., «Le gôut de Jean V: art et gouvernement», Bracara Augusta. Revista Cultural de Regionalismo e História da Câmara Municipal de Braga, vol. XXVII, 64 (76), 1973, págs. 341-464 (págs. 349 y 350), y AYRES DE Carvalho, A., João V e a arte do seu tempo. Lisboa: Mafra Agrícola, 1960, vol. II, en particular el capítulo III, págs. $241-311$. 
tonces demostraba el monarca su curiosidad omnívora. ${ }^{46}$ Merveilleux, en sus Mémoires instructifs, no deja dudas de su animadversión por el marqués de Fontes y lo señala como el principal culpable de la obsesión del rey por Roma; incluso apunta que influyó en la organización del viaje. ${ }^{47}$ Sea como fuere, lo que parece probado es que, en la corte de Juan V, sus representantes en el extranjero y otros nobles de su círculo fueron el caldo de cultivo ideal para la gestación del viaje europeo y fueron también vehiculares en el extraordinario plan de compra de obras de arte, libros, instrumentos científicos, partituras, etc. y en el acceso a la novedades del saber, política implementada desde el 1716 en adelante.

La amplitud del proyecto fallido era tal que, a pesar de la carencia de datos, existen claros indicios que demuestran que la naturaleza del mismo rompe con la tradicional visión de un tour concentrado en Italia, en concreto en Roma. La historiografía, como señala certeramente Raggi, ${ }^{48}$ ha sublimado Roma como la meta final y casi única del viaje sin atender a lo más obvio, esto es, que la ruta demuestra un interés por todas las cortes europeas, incluida la inglesa, y por tanto impera una visión, se podría decir, más «europeísta». Delaforce también señala Roma como objetivo último basándose en una cita de las cartas del nuncio, que dice: «essendo il suo único e principale oggetto il portarsi a Roma», pero es evidente que el nuncio no pudo sostener una posición tan parcial. ${ }^{49}$ Además del itinerario en sí, que sería suficiente para refutar una aproximación al viaje como un Grand Tour canónico, resulta esencial detenerse en un manuscrito titulado el $O$ Peregrino Instruído. Devem aquelles que por meio das viagens querem conhecer útilm..$^{\text {te }}$ o Mundo, informarse em cada Lugar do estado natural, Ecclesiástico, Político e Militar delle. Este manuscrito, conservado en la Biblioteca Nacional de Portugal, ${ }^{50}$ aparece también copiado en una miscelánea en la misma institución bajo el título: Modo com q se debe informar todo sugeito, q fizer giro pela Europa, e mais partes do Mundo. Mandadofazer na Occazião, $q$ S. Mages. ${ }^{\text {de }}$ o Sr. Rey D. João quinto esteve para ir incognito, ver as Cortes Estrangeiras y firmado por el monje teatino Manuel Caetano de Sousa. ${ }^{51}$

El Peregrino Instruído, por tanto, constituye una fuente preciosa y clarividente para analizar el viaje frustrado del Juan $\mathrm{V}$, aunque el hecho de que fuese anónimo ha llevado, según Ana Buescu, ${ }^{52}$ a que haya sido estudiado como una guía común para el viajero, cuando en realidad debería interpretarse como un pequeño manual al servicio de los intereses del rey. Partiendo de esta sólida hipótesis, la lectura del manuscrito descubre una concepción casi enciclopédica de lo que se puede y se debe aprender durante un viaje de esas características y es un interesante fruto de ese ambiente erudito ya citado. El rey encargó a Manuel Caetano de Sousa la redacción de dicho libro con motivo del viaje a Roma en 1709 para asistir al Capítulo General de los Clérigos Regulares, por lo que es plausible que ya entonces estuviese contemplando la posibilidad del viaje. ${ }^{53}$

La obrita se estructura como una serie de doscientas diez preguntas destinadas a obtener información pormenorizada del «estado moral» y del «estado natural» del territorio que se visita, sin distinción o mención específica al mismo, es decir, a pesar de haber sido una obra re-

46. Véase Diez Del Corral, P., «"A Lisbona, le spalle; a Roma, il volto”. Vieira Lusitano, un artista portugués en la Roma del Primo Settecento", en True, T.; Varela Braga, A. (eds.), Rome, a city of migrants. Dynamics of settlement and integration. Roma: Pensieri ad Arte - Artemide, 2018, págs. 189-202 y págs. 189-191.

47. Castelo Branco, C., O Portugal de D. João V visto por três forasteiros. Lisboa: Biblioteca Nacional, 1983 , pág. 151.

48. RAGGI, G., «La circolazione...», pág. 159, n. 8, para más referencias bibliográficas.

49. Delaforce, A., «Giovanni V...», pág. 28. Pimentel, A.F., Arquitectura e Poder. O Real Edifício de Mafra. Lisboa: Livros Horizonte, 2002, págs. 196-198. Analiza también el viaje pero no lo consideró demasiado relevante en el marco de su reinado.

50. Biblioteca Nacional de Portugal (BNP), Reservados, códice 618, fols. 1-8, y códice 674, fols. 259-264. Este último es el que aparece firmado.

51. Según la Bibliotheca Sousana (Lisboa, 1736), obra del conde de Ericeira, Caetano de Sousa llegó a publicar este librito como anónimo, pero no se conocen hasta la fecha ejemplares.

52. Buescu, A.I., «"O peregrino instruído”...», pág. 31.

53. Nótese que 1709 es también el año en el que nombra embajador extraordinario al marqués de Fontes. 
dactada en Roma, no está pensada solo para Roma. ${ }^{54}$ Conviene destacar la presencia importante de cuestiones relativas a lo religioso y eclesiástico, pero también a lo militar, lo político y lo económico, con especial atención a la arquitectura. Con esta guía, el «peregrino» sería capaz de construir una visión polifacética y profunda del territorio, que con toda certeza podría ser de utilidad práctica una vez de regreso a Portugal. En este sentido, el Peregrino Instruído, más que en la reduccionista interpretación de guía, encajaría mejor en un modelo de Breviarium imperii, libro instrumental que el emperador Augusto redactó para servir de base a su Administración, en el que se detallaban aspectos como la organización militar y financiera del Imperio, en el que se mencionaban impuestos, sueldos, tasas, número de soldados, gastos, etcétera. ${ }^{55} \mathrm{Y}$ no es casual que la obra de Sousa sea comparable al Breviarium imperii; en el primer año de reinado de Juan $\mathrm{V}$ se difundió una carta del expedicionario portugués Manuel Pinto Pereira dirigida al cardenal Annibale Albani, sobrino del papa, con manifiesta función propagandística. ${ }^{56}$ En dicha carta, entre otras cosas, se comenta que el rey se valía de un Breviarium imperii para manejar información de sus súbitos y tener un conocimiento profundo del territorio y sus materias primas, asegurando así la prosperidad del reino, al estilo de los emperadores romanos, sin duda una inteligente forma de erigirse en heredero del modelo imperial. ${ }^{57}$

El Peregrino Instruído no parece otra cosa que la base sobre la que organizar toda la información y conocimiento que esperaba poder obtener de su viaje. Lo pormenorizado y profundo de la serie de preguntas demuestra una intencionalidad muy clara de recabar datos prácticos sobre otros territorios con un valor formativo evidente, que encaja a la perfección en la idea del viaje educativo de los príncipes y caballeros centroeuropeos. En palabras del conde de Tarouca, entonces embajador en Londres enviado a La Haya para las negociaciones de paz, el rey se proponía «ver praças, marinhas, milícias. Exército, comércio, o génio das nações, ajustando artifices, professores para as ciências e artes que mais se ignoravam entre nós». ${ }^{58} \mathrm{El}$ conde, João Gomes da Silva, pertenecía también a ese círculo intelectual antes mencionado, y de hecho sería el que acogería al joven infante D. Manuel cuando este huyó de la corte en busca de fama aquel noviembre de $1715 \cdot{ }^{59} \mathrm{D}$. Manuel fue, de alguna manera, el beneficiario último de ese ambicioso proyecto. Y si bien no realizó el itinerario previsto por su hermano, sí pudo, en cambio, conocer las cortes de París, Viena y Roma, entre otras.

Aunque con el apoyo de D. Luís da Cunha llegó a negociar el perdón de su hermano y su regreso a Lisboa vía París, en el último momento D. Manuel decidiría poner rumbo a Viena y unirse al príncipe Eugenio de Saboya, que lideraba las tropas imperiales, para luchar contra los turcos en Hungría. Destacó en diferentes campañas militares y se convirtió en un héroe después de la batalla de Peterwardein y Temeswar, donde fue herido. Llegó a ser mariscal de campo y dirigió un regimiento de coraceros para el conde de Gronsfeld. En 1721 fue condecorado con el Toisón de Oro y en 1722 regresó a la corte francesa, donde volvió a ser acogido por D. Luís da Cunha, entonces destinado en París. ${ }^{60}$

54. En el códice 618 aparecen doscientas diez cuestiones, mientras que el códice 674 el número aumenta hasta doscientas doce.

55. Esta costumbre iniciada por Augusto fue seguida por otros emperadores romanos, por ejemplo Calígula, que publicó las cuentas del Imperio de esta manera.

56. BNP, Reservados, códice 13212/7. Copia de huma carta que escreveo Joseph Pinto Pereyra ao Excellentiss. Señ. D. Anibal Albani sobrinho de Sua Sanctidade (Lisboa, 1707).

57. La carta, y su valor propagandístico, fue estudiada por MARTín MARCos, D., «Beyond policy: shaping the image of John V of Portugal in Rome», en Diez del Corral Corredoira, p. (ed.), Politics and the Arts in Lisbon and Rome: The Roman dream of John V of Portugal. Oxford: The Voltaire Foundation (en prensa).

58. Dos SAntos, J.E., «Valioso subsídio...», pág. 6.

59. El conde de Tarouca sería acusado por el rey de instigar a D. Manuel a la desobediencia y acabaría relevado de su cargo en La Haya y obligado a regresar a Lisboa. BNP, Reservados, manuscrito 26, n. 30.

6o. La vida del infante transcurrió de aventura en aventura por Europa, lo que causó gran malestar a su hermano, el rey, que accedió a perdonarlo en otra ocasión y le permitió el retorno a Lisboa, de donde D. Manuel volvería a huir. Véase Dos SANTOS, J.E., «Valioso subsídio...», para más detalles. 
Los éxitos militares de D. Manuel lo convirtieron en un personaje conocido en las cortes europeas, pero fue la manera en la que decidió huir de Lisboa lo que lo persiguió toda su vida. El hecho de que un segundón de la casa real optase por la vida militar no tenía nada de sorprendente, de hecho el viaje formativo diseñado para los dos hermanos traía consigo un fuerte componente militar. Si se vuelve sobre el Peregrino Instruído, se ve que hay cuarenta y una preguntas destinadas a obtener datos precisos sobre la organización militar de los territorios, ${ }^{61}$ lo que demuestra el valor pragmático de esa estancia formativa por Europa. Existen múltiples precedentes de viajes similares para formar a los jóvenes príncipes: por ejemplo, en el ducado de Sajonia-Gotha, los descendientes del duque Ernesto el Pío (1601-1675), en concreto sus hijos Albert y Heinrich, hicieron viajes educativos a Utrecht, y su primogénito, Friedrich, viajó en 1662 también a Holanda, y en 1667 a Francia.${ }^{62}$ No resultaba, por tanto, extraño que en esos viajes se reuniese información sobre asuntos militares y se visitasen fortificaciones y bastiones, ya que se consideraba una parte esencial de la educación del príncipe. ${ }^{63}$

\section{CONSIDERACIONES FINALES}

Con certeza Juan V diseñó su particular Kavalierstour enormemente influido por la red de eruditos y/o diplomáticos que lo apoyaron en esos primeros años de juventud, muchos de ellos con suficiente carrera y experiencia como para recordar el viaje del elector sajón Federico Augusto, entonces rey de Polonia. Ese viaje, destinado a quedar irrealizado, fue, sin embargo, un recordatorio constante para el monarca de todo aquello que habría querido aprender in situ y a lo que debió renunciar.

El impacto que tuvo en sus decisiones posteriores a 1716 es un aspecto que necesita de mayor investigación y de una visión que abarque la enorme amplitud de miras que exhibía el monarca y que manifestó, por ejemplo, en su política cultural. Hasta la fecha este asunto se ha abordado parcialmente, si bien cabe destacar los estudios sobre Juan V e Italia, con especial atención a Roma, que sin duda fue el foco principal de sus intereses, aunque no el único. ${ }^{64}$

Una de las consecuencias más palpables todavía hoy, a pesar de las numerosas pérdidas de patrimonio artístico, librario, etcétera, a causa del terremoto de 1755, es la enorme impronta del gusto romano en la construcción del conjunto arquitectónico de Mafra o la valiosísima capilla dedicada a san Juan Bautista en la iglesia de São Roque (Lisboa), un verdadero trasplante de Roma al corazón de Lisboa. Entre las pérdidas irreparables estarían la Iglesia Patriarcal, con su ornamentación y su ajuar realizados ad hoc en la ciudad pontificia, y la magnífica colección de maquetas de monumentos y palacios de Roma, que decoraban uno de los salones del Paço da Ribeira (Palacio Real).

A pesar de lo que el azar del tiempo ha dejado en Lisboa, lo cierto es que Roma no era el único foco de atención, aunque sí el más intenso. Juan $\mathrm{V}$ emprendió numerosos proyectos que

61. Buescu, A.I., «"O peregrino instruído”...», pág. 43.

62. Thiele, A., «The Prince as Military Entrepreneur? Why smaller Saxon Territories sent "Holländische Regimenter” to the Dutch Republic», en Fynn-Paul, J., (ed.), War, Entrepreneurs, and the State in Europe and the Mediterranean, $1300-1800$. Leiden-Boston: Brill, 2014, págs. 170-192, pág. 178. También véase BENDER, E., «Die Prinzenreise», idem, págs. 229 y ss.

63. Incluso esto hacía que determinados países fuesen especialmente atractivos, por ejemplo, Holanda durante la guerra de los Ochenta Años. LeIBETSEDER, M., «Educational Journey...», pág. 11.

64. VAsco Rocca, S., Borghini, G.; Ferraris, P., Roma lusitana - Lisbona romana. Roma: Argos, 1990; BorGHINI, G.; VAsco RocCA, S. (eds.), Giovanni V di Portogallo (1707-175o) e la cultura romana del suo tempo. Roma: Àrgos, 1995; DELAFORCE, A., Art and Patronage in Eighteenth-Century Portugal. Cambridge: Cambridge University Press, 2002; DIEZ DEL Corral Corredoira, p. (ed.), Politics and the Arts... (en prensa). 
demostraban su voracidad por toda fuente de conocimientos y saberes y se valió de su estrecha red de diplomáticos y agentes repartidos por el mundo para atraer a Lisboa no solo los libros, las partituras, las pinturas o los instrumentos científicos, sino también a sus artífices para recrear en su capital todo aquel saber que no pudo recabar él mismo. Entre esas órdenes de compras, realizadas en su mayoría en los primeros treinta años de reinado, se puede destacar el proyecto de la colección de estampas, que debía de recoger toda la producción existente. El 12 de julio de 1724 el secretario de Estado, Corte-Real, manda una «circular» a todos los representantes lusos en las cortes europeas, incluida Rusia, para solicitar la creación de los volúmenes con la producción de estampas de las últimas tres décadas; un año después se amplía a toda la historia. ${ }^{65}$ La compra y creación de la colección sigue ordenadamente hasta 1727 , cuando ya iban por ciento seis volúmenes enviados a la corte. A finales de 1728 el rey tiene en sus manos ciento cincuenta volúmenes de la escuela francesa y ocho volúmenes de los grabados de Rubens, que consiguió D. Luís da Cunha, figura esencial en toda la iniciativa. ${ }^{66}$

Este fabuloso proyecto enciclopédico avant la lettre, destinado a la biblioteca real y perdido hoy casi por completo, forma parte de una visión mucho más amplia y original de lo que pudiera parecer. Su objetivo último era, sin duda, colocar a Portugal a la cabeza de Europa reuniendo todo el saber disponible en la época. Es probable que el ambicioso y joven Juan $\mathrm{V}$ quisiera inaugurar esta misión protagonizando un triunfal Kavalierstour, pero aunque este finalmente acabó como un mero propósito, sin embargo fructificó en numerosas obras e iniciativas desde su suntuosa corte a orillas del Tajo.

65. Mandroux-França, M.T.; PrÉAud, M. (eds.), Catalogues de la collection d'estampes de Jean V, roi de Portugal. París: Fundação Calouste Gulbenkian, 2003, pág. 55.

66. Mandroux-FrançA, M.T., «La collection d'estampes du roi Jean V de Portugal: une relecture des Notes Manuscrites de Pierre-Jean Mariette», Revue de l’Art, 73, 1986, págs. 49-54 (pág. 50). 